\title{
Characteristics and Pulmonary Computerized Imaging Findings of Critically Ill Egyptian Patients with Multisystem Inflammatory Syndrome in Children
}

\author{
Hanan Ibrahim ${ }^{1}$, Shaimaa Mohammad ${ }^{2}$, Eman Fouda ${ }^{1}$, Khaled Ahmed ${ }^{1}$, Nevin Habeeb ${ }^{1}$, \\ Ahmed Rezk ${ }^{1}$, Sondos Magdy ${ }^{1}$, Ahmed Allam ${ }^{2}$, and sanaa Mahmoud ${ }^{2}$ \\ ${ }^{1}$ Ain Shams University Faculty of Medicine \\ ${ }^{2}$ Ain Shams University
}

September 25, 2021

\begin{abstract}
Objectives. This study was carried out to delineate the patients' characteristics and the imaging findings and their relation to some biochemical markers of 31 critically ill patients with MIS-C. Design. A retrospective cross-sectional study including all critically ill MIS-C children admitted to the PICU from June 23rd to July 22nd, 2020. Results. Eighteen males and thirteen females, with a median age of 9 years (interquartile range 6-11) presented mainly with fever (100\%) and hypotension (100\%). Abnormalities in the chest computed tomography were detected in 22 cases (71\%). Consolidation and architecture distortion were detected in $58.1 \%$ of patients; bilateral lesions and lower lobe infiltrates, each, were evident in $64.5 \%$, while the peripheral distribution of lesions was seen in $71 \%$ of the cases. Pleural thickening and effusion were found in $51.6 \%$ of the patients. In this small case series, the presence of high ferritin was significantly associated with the bilaterality of the lesions. Elevated C-reactive protein was associated with the peripheral distribution of the lesions, in addition, thrombocytopenia and hypoalbuminemia were significantly correlated with the CT disease stage and CT severity score respectively. Conclusions. Short and long-term follow up of MIS-C cases is not only needed for the follow up of clinical and laboratory abnormalities but also for the elucidation of the outcome of CT pulmonary findings.
\end{abstract}

\section{Hosted file}

The CT manuscript for Ped Pulm new.docx available at https://authorea.com/users/437172/ articles/538993-characteristics-and-pulmonary-computerized-imaging-findings-ofcritically-ill-egyptian-patients-with-multisystem-inflammatory-syndrome-in-children

\section{Hosted file}

The manuscript table 1 ped pulm.docx available at https://authorea.com/users/437172/articles/ 538993-characteristics-and-pulmonary-computerized-imaging-findings-of-critically-illegyptian-patients-with-multisystem-inflammatory-syndrome-in-children 

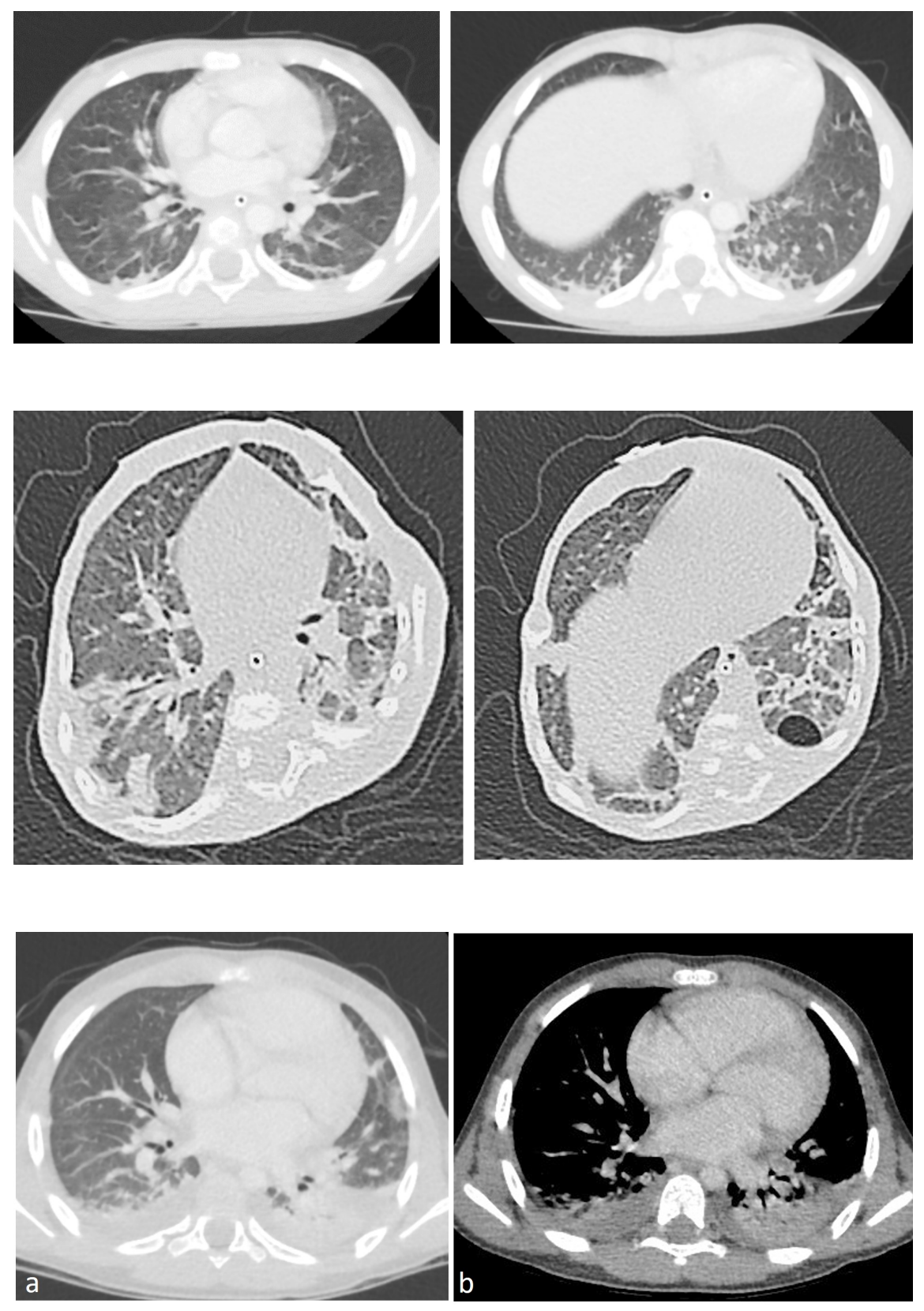

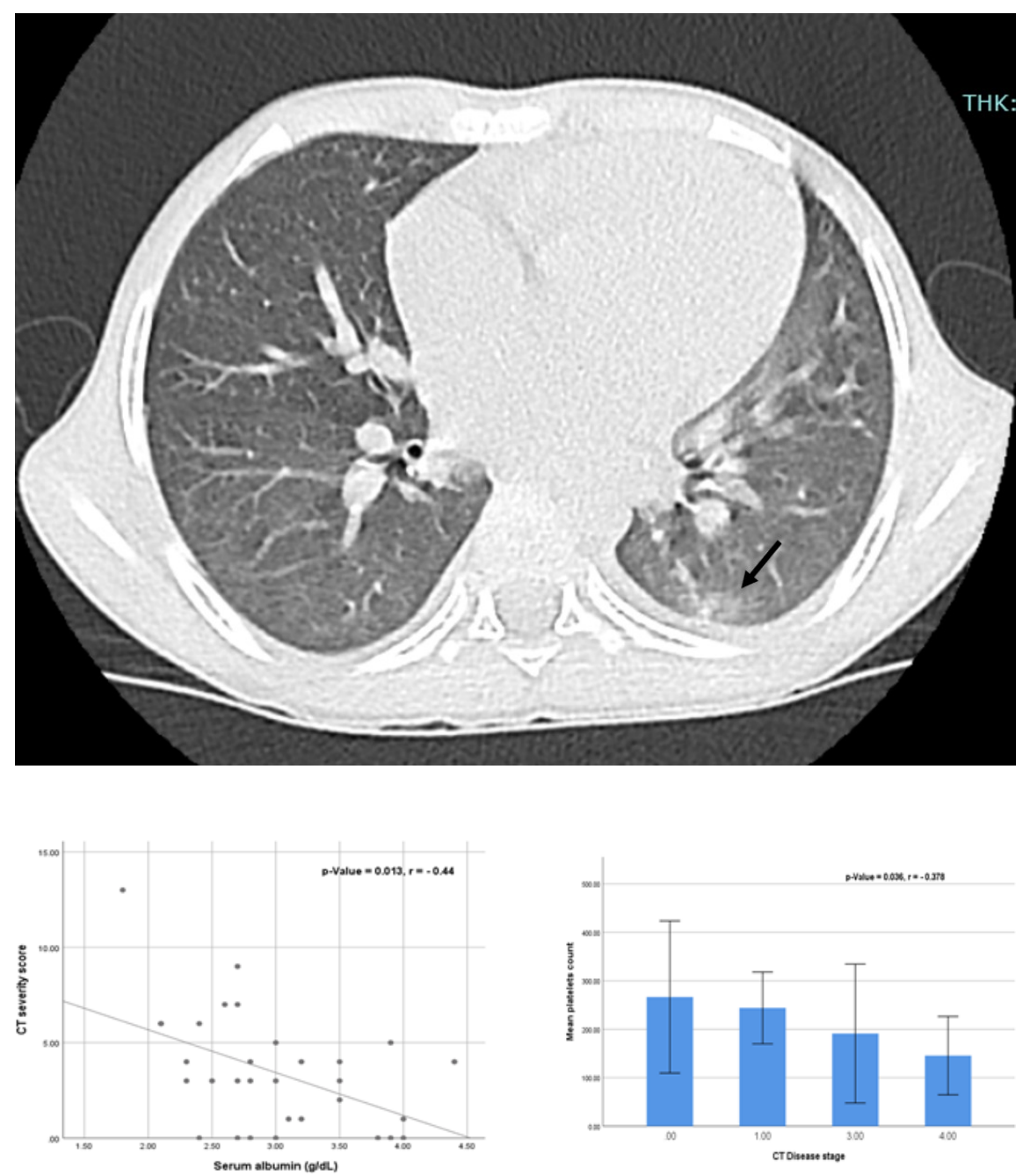